\title{
Monitoring the diversity of malaria and dengue vector in Karachi: studying variation of genera and subgenera of mosquitoes under different ecological conditions
}

\author{
Saima Shaikh', Syed Jamil H Kazmi ${ }^{1}$ and Salman Qureshi $i^{2,3^{*}}$
}

\begin{abstract}
Introduction: Karachi, a city of unique terrain and moderate tropical climate, is home to several mosquito species. The geographical distribution and density of these species may vary within the city, owing to their interaction with an ever-increasing population and urban settings. As a consequence, the prevalence of vector-borne diseases is unpredictable within the geographical limits of Karachi city. In this spatiotemporal study, 1,156 mosquito samples were collected from 50 study sites with unique ecological characteristics within the city and a taxonomical exercise was conducted to investigate different vector species thriving in different months and seasons of the year. The main genera of mosquitoes were identified and categorized using a pictorial key based on the standard guidelines of the Walter Reed Biosystematics Unit, substantiated with ancillary literature.
\end{abstract}

Results: Three important genera were found in Karachi: Anopheles, Aedes and Culex. Important subgenera were subsequently identified, based on their susceptibility to major vector-borne diseases. January had the highest concentration of adult mosquitoes, as the colder weather conditions were suitable for breeding. May recorded the lowest number, owing to excessively hot weather when most of the breeding pockets had dried out; less vegetation (in pre-monsoon conditions) prevented mosquito growth.

Conclusions: Slum areas showed an abundance of malaria and dengue vectors, owing to poor hygiene conditions caused by open sewage drains. Hence, a major precaution is to raise awareness among people about mosquito-borne diseases. The breeding habitats of these vectors should be studied using geospatial technologies to improve spatial and temporal coverage.

Keywords: landscape ecology; mosquito species; spatial epidemiology; spatial variation; urban ecology; urban habitat; vector-borne diseases

\section{Introduction}

Vector-borne diseases have been proven as major contributors of death and illness in many developing countries in the world. The eradication efforts to control these ailments do not match the high dispersion rate of these diseases. There have been several instances of a resurgence of these vector-borne diseases in many developing

\footnotetext{
*Correspondence: salman.qureshi@geo.hu-berlin.de

${ }^{2}$ Department of Geography (Landscape Ecology), Humboldt University of Berlin, Rudower Chaussee 16, Berlin 12489, Germany

${ }^{3}$ School of Architecture, Birmingham City University, The Parkside Building, 5 Cardigan Street, Birmingham B4 7BD, UK

Full list of author information is available at the end of the article
}

countries, such as Pakistan. The dispersion of vectors, parasites and viruses is irrepressible because of the movement of susceptible hosts from one place to another (Kazmi and Pandit 2001). Because of this mobility, many diseases, such as dengue, have now expanded their area of influence towards areas where such diseases were not prevalent before (World Health Organization 2012). New strains of these diseases are found in highly unlikely places and more people are susceptible to these vector-borne diseases in many places around the world. As a consequence, parasites and vectors have dispersed to entirely new locations (World Health Organization 2012). Pakistan is no 
exception, as malaria is at significant levels of resurgence (Zaidi and Kazmi 2010), along with rapidly expanding diseases, such as dengue (Shaikh 2010). For example, dengue viruses reached Karachi, Pakistan, from Bangladesh through Bengali workers immigrating in the 1990s (Chan et al. 1995). The dengue virus dispersed from Karachi to Swat (a high altitude northern district in the Khyber Pakhtunkhwa province of Pakistan), resulting in high morbidity and mortality rates there. Malaria and dengue are serious threats for the world population and have already taken a high death toll. In 2010, estimated deaths from malaria were about 655,000 , out of which $86 \%$ were reported to be among children younger than 5 years (World Health Organization 2011). Approximately 216 million cases were reported in the year 2010 alone (World Health Organization 2011). Being a subtropical country, Pakistan is significantly diversified in mosquito fauna, where three important genera of mosquitoes were reported, including Anopheles (An.), Aedes (Ae.) and Culex (Cx.) (Nalin et al. 1985). Anopheles has 26 subgenera, which are considered carriers of malaria in Pakistan (Kazmi 1997), as well as in several other parts of the world. Besides Anopheles, several subgenera of Aedes and Culex were also reported to be found in Pakistan (Aslamkhan 1971).

Karachi, the largest city of Pakistan and a city of unique terrain and moderate tropical climate, is home to several mosquito species. The geographical distribution and density of these species vary within the city, owing to their interaction with a growing population forming new urban habitats (Kazmi and Usery 2001). The rural population, in the periphery of Karachi, has a comparatively different variety and concentration of mosquitoes. As a consequence, the prevalence of vector-borne diseases is unpredictable within the geographical limits of Karachi city. Karachi is surrounded by mountains on three sides and borders the Arabian Sea in the south. Therefore, the major expansion of the city is in the northern and eastern directions, providing room for new settlements. Although the city has overall arid climatic conditions overall, it receives monsoon rainfall during the months of July to September; this climate supports diverse breeding habitats.

Karachi provides ideal habitats for vectors of diseases such as Anopheles, as a malaria vector, and Aedes, as a

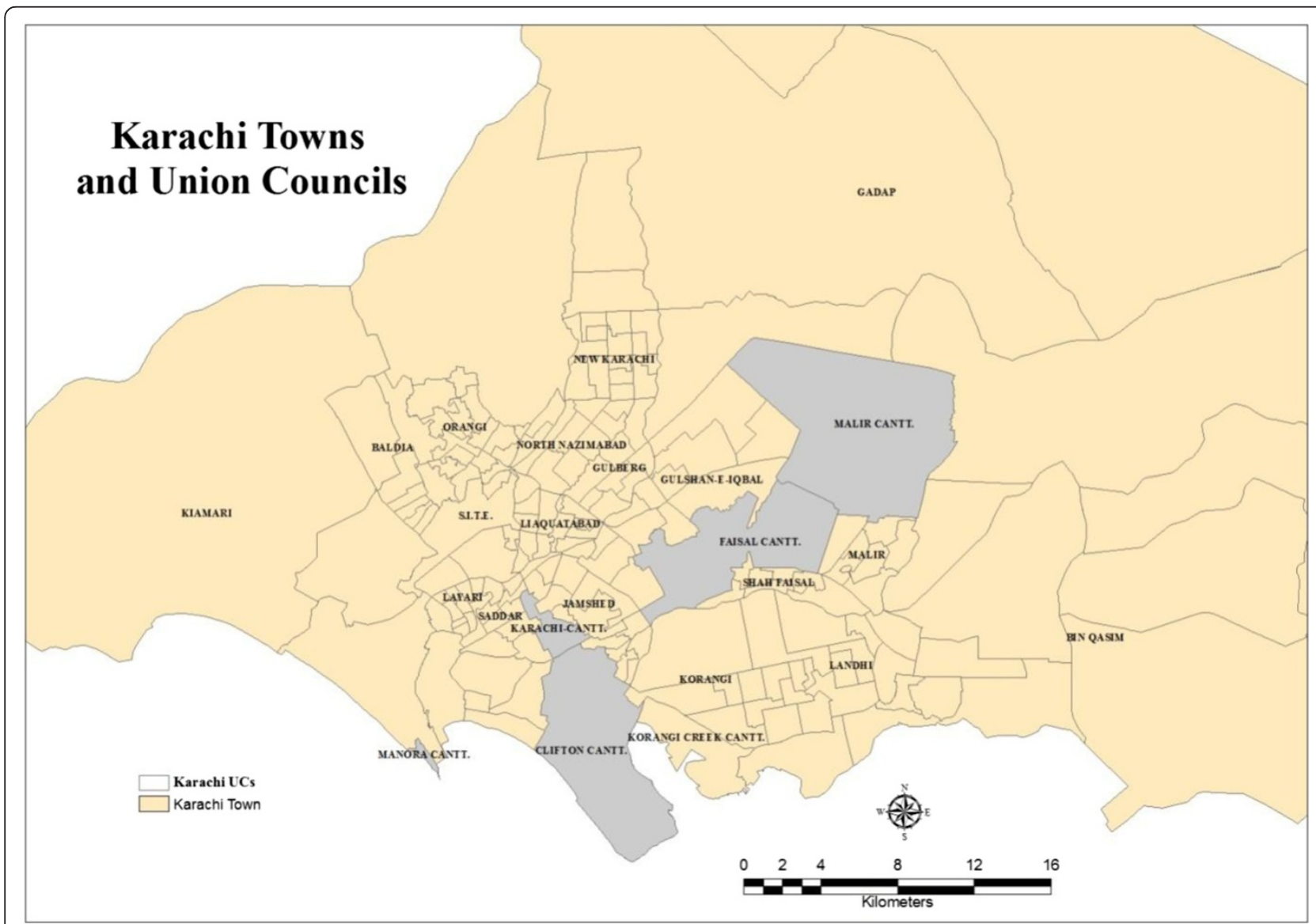

Figure 1 Study area (Karachi with its administrative settings). 
dengue carrier (Shaikh 2010). Culex is found in abundance, especially in comparison with Anopheles and Aedes, which account for significantly lower portions of mosquito fauna in Karachi (Kazmi 1997; Shaikh 2010;). It is important to mention that any accidental transport of yellow fever parasites in Karachi may cause new epidemics of this disease to break out. Culex is not only abundant in Karachi but also widespread in other parts of Pakistan, causing such diseases as filariasis, and. Tahir et al. (2009) reported the abundance of Culex quinquefasciatus, which might be the carrier of these diseases, in several areas of Lahore. After Culex, the second major contributor of mosquito fauna in Karachi is Anopheles followed by Aedes species (Shaikh 2010). In Karachi, four subgenera were found responsible for the transmission of malaria, namely, An. stephensi, An. culicifacies, An. subpictus and An. superpictus (Zaidi and Kazmi 1997;). Qamar (2005) reported An. stephensi, An. culicifacies and An. subpictus as the actual carriers of malaria in urban and rural areas of Karachi. Aedes aegypti is the only carrier of dengue fever in Karachi, while Aedes albopictus has been reported as a carrier of dengue fever in many parts of the Punjab province (Khan et al. 2011).
The main objective of this study is to identify the major habitats of malaria and dengue vectors (An. culicifacies, An. stephensi, An. superpictus, An. subpictus and Ae. aegypti) in Karachi. Their abundance was quantified to analyze their share in total mosquito catches and their seasonal variations. We investigated the variation of three major genera of mosquitoes in selected areas of Karachi. Furthermore, the spatial variations of subgenera of malaria and dengue vectors in Karachi have also been investigated.

\section{Methods}

Karachi city has been selected as the study area. It is a city accommodating over 18 million people and occupies an area over 3,500 km² (Kazmi et al. 2012). Karachi city district is divided into 18 administrative towns, which are further subdivided into 178 union councils (Figure 1). The city, due to its ever-increasing population, large spatial extent and subtropical location, is home to several socio-ecological challenges to human life along the urban gradient (Qureshi et al. 2010a, b; Qureshi 2010).

To select sampling sites and collect adult mosquitoes, the study area was divided into major economic strata based on the size of housing units and population density.

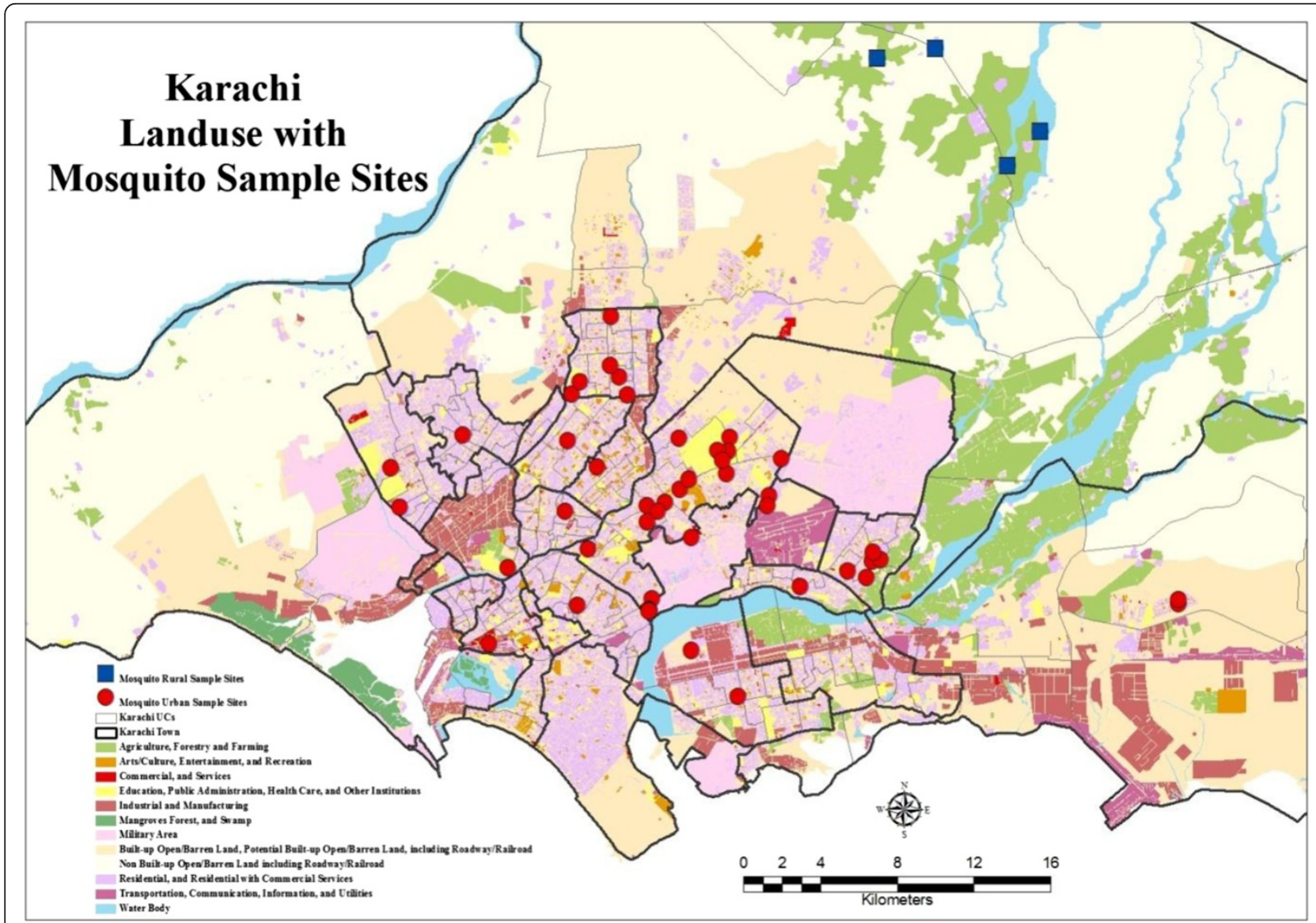

Figure 2 Sampling locations shown on the land-use map of Karachi. After Naqi (2010). 


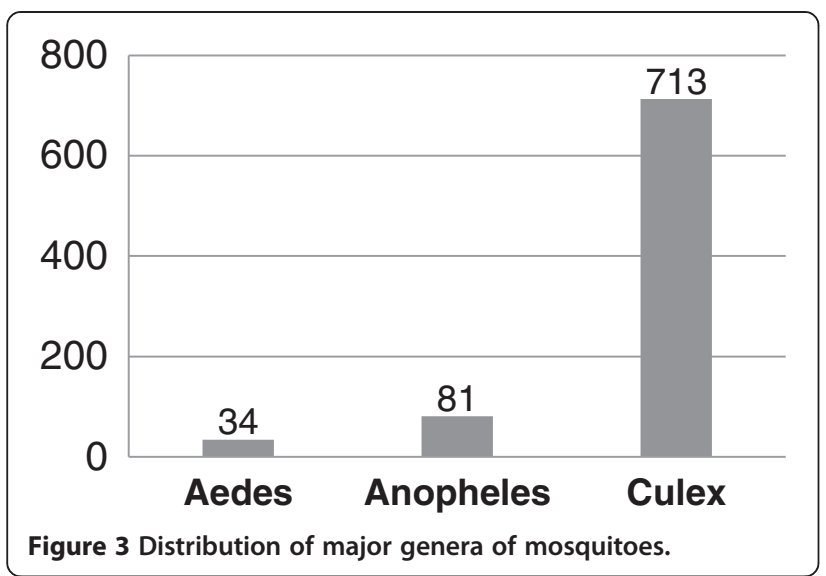

This was supported by evaluating the land-use characteristics of Karachi studied through high-resolution remotely sensed data. The land-use categories were primarily developed in the context of their relevance to the mosquito habitat. Therefore, our classification included vegetation cover, water bodies, slum areas and open spaces (open barren land is considered to be an intrinsic element of typical mosquito habitats). The land-use pattern was the major element that assisted in identifying 50 sampling sites (Figure 2). A radial buffer of $250 \mathrm{~m}$ (that is, the actual known flight range of the target species) was developed around each site.

These sampling sites, owing to their unique geographical characteristics (including most dominant land-uses or types of land cover and a mixture of urban services) were identified so that a widest possible range of distinct urban neighbourhoods could be used to identify mosquito habitats. Mosquito samples were collected from these sampling sites by trained field assistants (who were postgraduate research students). Samples were collected from the first to the tenth of every month. These dates were planned to keep our datasets temporally consistent and to produce a normalized geodatabase. The adult mosquito samples were collected at dawn and dusk, as this is the time when mosquitoes are highly active and are found abundantly. We used mosquito killer sprays to collect mosquitoes and try to preserve their body parts; if the mosquitoes were damaged, they could not be identified correctly. The dead mosquitoes were collected in glass bottles and later preserved in alcohol solution, which consisted of $30 \%$ alcohol and $70 \%$ distilled water.
Alcohol solution at this concentration usually preserves the samples for a longer period of time. For identification, collected samples were initially dried and then sample slides (using thin films) were developed for each mosquito species. These slides were studied under a binocular microscope (Vision V4000). The samples of mosquitoes were further verified randomly by an expert in entomology (Professor Dr Ansar Rizvi) at the Entomology Laboratory of the Department of Zoology, University of Karachi.

The Walter Reed Biosystematics Unit (2001) was used as a major identification manual but it was supported by some other pertinent guidelines (for example, Ross and Roberts 1943; Rueda 2004) to improve the identification process, customized to local conditions. Subgenera were identified mainly on the basis of their taxonomic structures, such as the head, thorax, abdomen and wings. The most important vector genus, Anopheles, is abundantly found in both the tropical and subtropical areas of the world. The data of identified species were then recorded in a spreadsheet database to analyze the variation of mosquito catches, particularly of Anopheles and Aedes.

To investigate the spatial variation of the mosquito species, we used the inverse distance weight to explore the distribution pattern of mosquitoes. This technique statistically determines the proximity of the sample (mosquito species in our case) through nearest distance weights of concentration of the samples. It is usually very effective in highlighting clusters of species and high or low density pockets are much easier to identify.

\section{Results and discussion}

Of 1,156 samples collected, 828 mosquitoes were included for an in-depth physical examination and taxonomical studies to identify their genera (Figure 3). After identification of Anopheles, Aedes and Culex, the data were arranged monthly to monitor the seasonal/temporal variation. The monthly collection of mosquitoes shows that among all the collected samples Culex were found in higher numbers than the other genera, although their counts were affected by a seasonal shift. Aedes and Anopheles showed noticeable seasonal variation in their subsequent catches (Table 1).

Three main genera that were found in Karachi are Anopheles, Aedes and Culex. Among these, subgenera

Table 1 Monthly variation of mosquito genera

\begin{tabular}{|c|c|c|c|c|c|c|c|c|c|c|c|c|c|}
\hline Genus & January & February & March & April & May & June & July & August & September & October & November & December & Total \\
\hline Anopheles & 14 & 10 & 7 & 3 & 3 & 13 & 7 & 10 & 0 & 1 & 1 & 12 & 81 \\
\hline Aedes & 0 & 0 & 1 & 1 & 1 & 1 & 1 & 7 & 6 & 10 & 4 & 2 & 34 \\
\hline Culex & 138 & 103 & 89 & 50 & 42 & 21 & 23 & 64 & 50 & 37 & 30 & 66 & 713 \\
\hline Total & 152 & 113 & 97 & 54 & 46 & 35 & 31 & 81 & 56 & 48 & 35 & 80 & 828 \\
\hline
\end{tabular}


Table 2 Mosquito genera and subgenera variation in sample sites

\begin{tabular}{|c|c|c|c|c|c|c|c|c|c|}
\hline Sample site & Town & Anopheles & Aedes & Culex & An. stephensi & An. culicifacies & An. subpictus & An. superpictus & Ae. aegypti \\
\hline 1 & Baldia & 0 & 0 & 9 & 0 & 0 & 0 & 0 & 0 \\
\hline 2 & Bin Qasim & 3 & 0 & 7 & 0 & 3 & 0 & 0 & 0 \\
\hline 3 & Bin Qasim & 0 & 0 & 12 & 0 & 1 & 0 & 0 & 0 \\
\hline 4 & Faisal Cant & 2 & 0 & 25 & 0 & 2 & 0 & 0 & 0 \\
\hline 5 & Faisal Cant & 1 & 0 & 3 & 0 & 1 & 0 & 0 & 0 \\
\hline 6 & Faisal Cant & 0 & 0 & 1 & 0 & 0 & 0 & 0 & 0 \\
\hline 7 & Gadap & 0 & 0 & 3 & 0 & 0 & 0 & 0 & 0 \\
\hline 8 & Gadap & 4 & 0 & 4 & 0 & 1 & 0 & 0 & 0 \\
\hline 9 & Gadap & 1 & 0 & 1 & 0 & 0 & 0 & 1 & 0 \\
\hline 10 & Gadap & 0 & 0 & 0 & 0 & 0 & 0 & 0 & 0 \\
\hline 11 & Gulberg & 4 & 0 & 14 & 0 & 0 & 0 & 0 & 0 \\
\hline 12 & Gulshan-e-lqbal & 8 & 0 & 42 & 2 & 3 & 0 & 1 & 0 \\
\hline 13 & Gulshan-e-lqbal & 0 & 0 & 7 & 0 & 0 & 0 & 0 & 0 \\
\hline 14 & Gulshan-e-lqbal & 2 & 0 & 9 & 1 & 1 & 0 & 0 & 0 \\
\hline 15 & Gulshan-e-lqbal & 0 & 0 & 1 & 0 & 0 & 0 & 0 & 0 \\
\hline 16 & Gulshan-e-lqbal & 0 & 0 & 1 & 0 & 0 & 0 & 0 & 0 \\
\hline 17 & Gulshan-e-lqbal & 0 & 0 & 5 & 0 & 0 & 0 & 0 & 0 \\
\hline 18 & Gulshan-e-lqbal & 0 & 0 & 4 & 0 & 0 & 0 & 0 & 0 \\
\hline 19 & Gulshan-e-lqbal & 0 & 0 & 9 & 0 & 0 & 0 & 0 & 0 \\
\hline 20 & Gulshan-e-lqbal & 0 & 0 & 12 & 0 & 0 & 0 & 0 & 0 \\
\hline 21 & Gulshan-e-lqbal & 0 & 0 & 11 & 0 & 0 & 0 & 0 & 0 \\
\hline 22 & Gulshan-e-lqbal & 0 & 0 & 10 & 0 & 0 & 0 & 0 & 0 \\
\hline 23 & Gulshan-e-lqbal & 3 & 0 & 94 & 4 & 3 & 0 & 0 & 0 \\
\hline 24 & Gulshan-e-lqbal & 1 & 5 & 0 & 1 & 0 & 0 & 0 & 5 \\
\hline 25 & Gulshan-e-lqbal & 2 & 0 & 28 & 0 & 1 & 0 & 0 & 0 \\
\hline 26 & Gulshan-e-lqbal & 1 & 0 & 6 & 1 & 0 & 0 & 0 & 0 \\
\hline 27 & Gulshan-e-lqbal & 0 & 0 & 41 & 0 & 0 & 0 & 0 & 0 \\
\hline 28 & Gulshan-e-lqbal & 2 & 0 & 3 & 0 & 2 & 0 & 0 & 0 \\
\hline 29 & Gulshan-e-lqbal & 6 & 0 & 15 & 0 & 0 & 0 & 0 & 0 \\
\hline 30 & Jamshed town & 0 & 0 & 34 & 0 & 2 & 0 & 0 & 0 \\
\hline 31 & Kemari & 0 & 0 & 6 & 0 & 0 & 0 & 0 & 0 \\
\hline 32 & Korangi & 3 & 0 & 20 & 0 & 1 & 0 & 0 & 0 \\
\hline 33 & Korangi town & 3 & 3 & 28 & 1 & 2 & 0 & 0 & 3 \\
\hline 34 & Liaquatabad & 1 & 0 & 45 & 0 & 0 & 0 & 0 & 0 \\
\hline 35 & Malir & 3 & 6 & 12 & 1 & 1 & 0 & 0 & 6 \\
\hline 36 & Malir & 0 & 0 & 1 & 0 & 0 & 0 & 0 & 0 \\
\hline 37 & Malir & 0 & 0 & 23 & 0 & 0 & 0 & 0 & 0 \\
\hline 38 & Malir & 3 & 0 & 3 & 0 & 3 & 0 & 0 & 0 \\
\hline 39 & Malir & 0 & 0 & 7 & 0 & 0 & 0 & 0 & 0 \\
\hline 40 & North Karachi & 1 & 0 & 0 & 0 & 1 & 0 & 0 & 0 \\
\hline 41 & North Karachi & 0 & 0 & 2 & 0 & 0 & 0 & 0 & 0 \\
\hline 42 & North Karachi & 5 & 0 & 4 & 0 & 1 & 1 & 0 & 0 \\
\hline 43 & North Karachi & 13 & 0 & 4 & 0 & 11 & 0 & 0 & 0 \\
\hline 44 & North Karachi & 0 & 5 & 35 & 0 & 0 & 0 & 0 & 5 \\
\hline
\end{tabular}


Table 2 Mosquito genera and subgenera variation in sample sites (Continued)

\begin{tabular}{llllllllll}
\hline 45 & North Karachi & 1 & 2 & 39 & 1 & 0 & 0 & 0 & 2 \\
46 & North Nazimabad & 0 & 0 & 3 & 0 & 0 & 0 & 0 & 0 \\
47 & Orangi & 6 & 9 & 26 & 1 & 0 & 3 & 0 & 0 \\
48 & Saddar & 0 & 4 & 28 & 0 & 0 & 4 & 0 & 0 \\
49 & Shah Faisal & 5 & 0 & 16 & 0 & 1 & 0 & 0 \\
50 & SITE & 4 & 0 & 14 & 3 & 4 & 0 \\
\hline
\end{tabular}

that are the main vectors of diseases (in the context of public health) were sought out on the basis of their disease transmission in the area. Of all the collected Anopheles species, An. stephensi is an important malaria carrier in Karachi (Kazmi 1997). Anopheles is the most important disease carrying mosquito genus throughout history, and has seriously caused the transmission of malaria disease in Pakistan (Aslamkhan 1971; Kazmi and Pandit 2001) and other parts of the world. The subgenera of Anopheles that were also identified and mainly found were An. stephensi, An. culicifacies, An. subpictus and An. superpictus (Table 2).

It is an established fact that the breeding habitats of mosquitoes are significantly correlated with distinct land-use and land-cover types (Shaikh 2010; Kazmi 1997). Vegetation, water, population density, built-up land, slum areas, and so on (Kazmi 1997), are positively correlated with mosquito prevalence. In this study, we found a significant relationship between mosquitoes and vegetation, water bodies, open green areas and built-up areas by integrating satellite image classification and field-based sampling methods.

An. stephensi was found mainly in sewage water but also in freshwater habitats and is very well adapted to the local environment of Karachi. It holds approximately a 35\% share of the total catches of Anopheles. Its concentration was higher in low-income or slum areas of Karachi, such as Orangi and low-income areas of Gulshan-e-Iqbal town. Other areas were observed to have a very low number of An. stephensi but, compared with other Anopheles species, there numbers were still very high. An. culicifacies is the most important subgenus of mosquitoes in the local context and is the most abundant (40\% of the total) Anopheles species found in all the collected catches of Karachi. However, the identification of An. culicifacies is relatively complex because most of its features resemble other subgenera; in particular, its leg pattern resembles that of An. superpictus. Nevertheless, the habitats of An. culicifacies are usually quite different and local knowledge of the geographical characteristics of the habitats led to better taxonomic identification.

An. superpictus is actually a weak carrier of malaria and a typical rural mosquito species (Fischhoff et al.
2002). It was mainly found in open rural areas, such as Gadap, which are located in the outskirts of metropolitan areas of Karachi. To identify An. superpictus, the mesonotum is a quite useful body, which is fully covered with narrow, pale scales, and the wings, which are composed of major pale-white bands. Similarly, the abdomen and legs are very useful for the identification of this sporadically found species (Ross and Roberts 1943). Of all 50 sampling sites, only two areas were identified as the habitat of An. superpictusand have typical rural settings. An. subpictus are also weak carriers of malaria in the study area (Shaikh 2010). They are abundantly found in hilly and open areas, and these species are also found in the Baluchistan province of Pakistan. The most important taxonomic features are wing scales, which are much larger than in other genera; the leg bands are also very easy to identify in this species. For identification of this rare species, wings are very good indicators; they have black spots, not in very high numbers but have distinctive variability in the costa with four or more pale dots on it (Ross and Roberts 1943). In Karachi, An. subpictus is only found in Baldia town, bordering the eastern part of Baluchistan province.

The seasonal variation of mosquitoes drives the incidence of malaria and dengue. The monthly variation of mosquito concentration is always associated with climatic variation, especially the pre- and post-monsoon seasons. Culex outnumbered Aedes and Anopheles in the periodic catches of mosquitoes (Figure 4). From January to May, the total numbers of mosquitoes caught were very high (Table 1). It was observed that mosquito counts declined significantly when the season shifted, from June to July, but again increased between August and December. The highest number of mosquitoes was recorded in January because of the cold temperatures; mosquitoes try to enter relatively warmer houses and survive on human blood, hence resulting in disease dispersion during this month.

Beside the seasonal change in the total number of mosquitoes collected, the other most important and noticeable fact is the interesting seasonal shift in the counts of Anopheles and Aedes. If we compare the counts of Anopheles and Aedes, two major spells were clearly observed. The first one was based on the highest ratio of Anopheles 


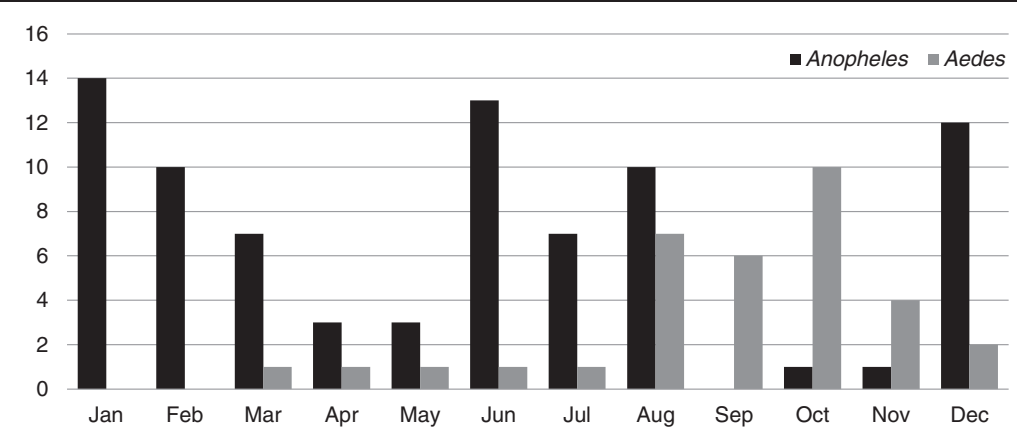

Figure 4 Monthly variation in genus Anopheles and genus Aedes counts.

from January to August and then in December. The second starts from August and lasts until December (the highest ratio of Aedes was observed during this period). Beside this observation, some overlapping months were also identified, showing higher concentration for both Anopheles and Aedes species.

These seasonal changes in mosquito abundance were mainly associated with the shift in rainfall, temperature and humidity (Figure 5). From July to September, Karachi usually receives maximum rainfall due to monsoon, resulting in stagnant rainwater, serving as breeding grounds for mosquitoes. During the drier season in October, the mosquitoes shift their habitats from dried areas in the city to overhead storage tanks and thrive there until the next monsoon season. Their density significantly decreases in the warmer months of May and June and sometimes drops to zero.

The agglomerated pockets of Anopheles were mainly observed in the north-east part of Karachi having low and middle income areas. North Karachi and north Nazimabad are the main foci of the diseases because of the overwhelming numbers of overhead tanks and open sewerage lines, which serve as an ideal habitat for mosquitoes. This species were also found in well water in the rural areas of Gadap.

The diversity of Aedes mosquitoes in Karachi reflects a completely different distribution, showing high clusters in the north-west and south-east of Karachi. The lowincome areas are the target of Aedes with Baldia and Korangi as the major hub, where open drains, water pitchers and overhead water reservoirs serve as major sources for breeding. It has been revealed from the spatial variation of mosquito breeding grounds in Karachi that the high incidence of vector-borne diseases is associated with low-income areas of the city. This is mainly because of poor health and sanitation conditions (for example, open sewage drains and unpaved roads resulting in standing rainwater). Furthermore, the high incidence of vector-borne diseases has also been noticeably increased in rural settings areas, where there is a general dearth of health facilities.

The concentration of Culex genera is quite ubiquitously found in almost every part of Karachi, with greater densities in the west and south. Surprisingly, Culex

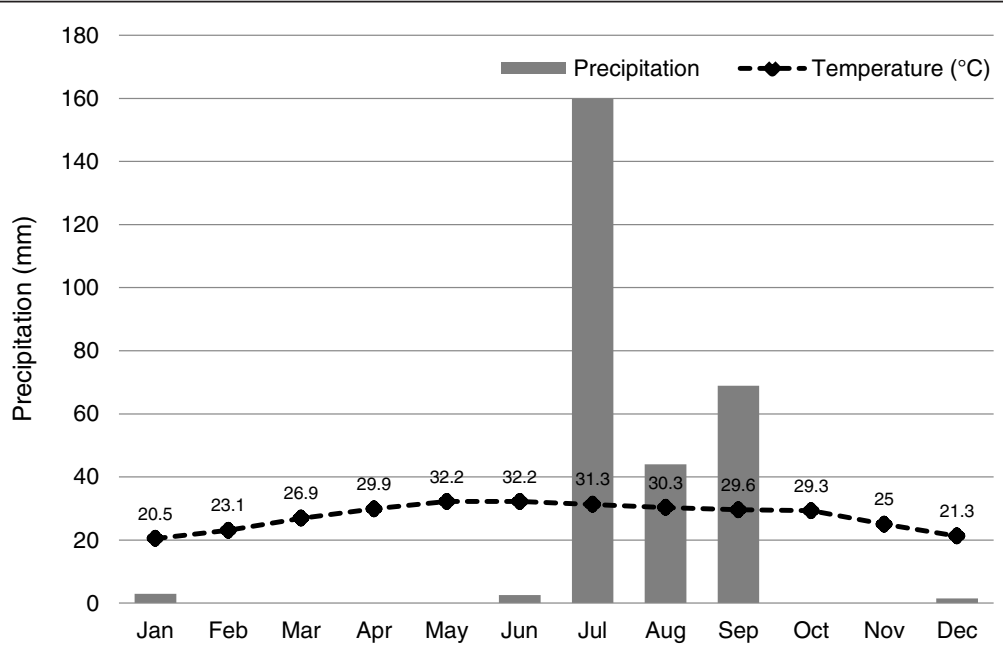

Figure 5 Average monthly temperature and precipitation of Karachi. (Pakistan Meteorological Department Temperature and Rainfall variation of Karachi (2009) unpublished data). 
were recorded in high numbers in the same areas that of Anopheles and Aedes, but they may vary seasonally in comparison with these disease carriers (Anopheles and Aedes). After the identification of subgenera of Anopheles, we further investigated the subgenera of Aedes but we only found Aedes aegypti as a subgenus of Aedes.

\section{Conclusion}

This study proved that slum areas showed an abundance of malaria and dengue carriers, owing to poor hygienic conditions caused by open sewage drains. Hence, a major precaution is to raise awareness among people about mosquito-borne diseases and also identify the breeding habitats of the vectors of these diseases using state-of-theart scientific methods, such as geospatial technologies, to improve spatial and temporal coverage of the data. It is significantly important to conduct consistent studies on different mosquito-borne diseases, specifically focusing the vector identification with particular focus on their habitat types and location. These studies should be conducted periodically, involving qualified researchers, health practitioners and government health departments. Furthermore, the awareness of such ailments must be improved among residents, so that they can appropriately cope with such challenges.

Keeping in view the large population of Karachi and its spatial extent, the sample size studied in this paper might be considered relatively small, that is, about 1,156 adult mosquitoes out of which only 115 were vectors of the two prominent diseases. It might be considered as generalization in comparison to the on-ground situation. However, this study was an exploratory attempt to test the methodology and legitimacy of some understudied questions; it is recommended that the same methodology be tested with a larger sample size. A cross-city comparative study is also recommended to develop a nation-wide regional understanding of the problem. Furthermore, data collection should be conducted from more sampling sites representing distinct ecological zones (as developed by the authors). It would help to further strengthen indigenous vector data knowledge

Most of the vector-borne diseases are multifaceted in nature; that is why, in the context of vector, host and parasite, the authors strongly believe that multidisciplinary studies in ecology, epidemiology, geography, and so on, should be conducted to improve understanding regarding controlling measures of the disease in affected areas of Pakistan. In this context, the Vector Control Boards that were established in the 1970s should be rejuvenated, so as to function effectively. The spatial jurisdiction of these boards should be the entire district, where the management should be given the authority to monitor the whole district (including municipal and cantonment) for effective decision making to handle the problem.

\section{Competing interests}

The authors declare that they have no competing interests.

\section{Authors' contributions}

SS conceived the study, collected and analyzed the data and wrote the first draft of the manuscript. SJHK conceived and supervised the study and wrote and edited the manuscript. SQ conceived the study, structured the methodology and wrote and edited the manuscript. All authors read and approved the final manuscript. We are thankful to Computerized Data Processing Center (CDPC), Pakistan Meteorological Department (PMD) for providing weather data of Karachi used in Figure 5.

\section{Acknowledgements}

We are grateful to all those individuals who helped in mosquito sample collection from various locations of Karachi. We are especially thankful to Dr Ansar Rizvi, Department of Zoology, University of Karachi for his support and guidance throughout this work. This research was supported in part by a grant provided by the Dean Faculty of Science, University of Karachi.

\section{Author details}

${ }^{1}$ Department of Geography, University of Karachi, Karachi 75270, Pakistan. 2Department of Geography (Landscape Ecology), Humboldt University of Berlin, Rudower Chaussee 16, Berlin 12489, Germany. ${ }^{3}$ School of Architecture, Birmingham City University, The Parkside Building, 5 Cardigan Street, Birmingham B4 7BD, UK.

Received: 11 March 2014 Accepted: 16 April 2014

Published online: 08 August 2014

\section{References}

Aslamkhan M (1971) Mosquitoes of Pakistan: a checklist. Mosq Syst Newsletter 3(4):147-159

Chan YC, Salahuddin NI, Khan J, Tan HC, Seah CL, Li J, Chow VT (1995) Dengue haemorrhagic fever outbreak in Karachi, Pakistan, 1994. Trans R Soc Trop Med Hyg 89:619-620

Fischhoff B, Fischhoff LR, Casman EA, Dowlatabadi H (2002) Integrated assessment of malaria risk. In: Casman EA, Dowlatabadi H (eds) The contextual determinants of malaria. Resources for the Future Press Book, Washington, DC, USA

Kazmi SJH (1997) Incidence of malaria in Pakistan: a geographical analysis. PhD dissertation, Department of Geography, University of Karachi, p 271

Kazmi JH, Pandit K (2001) Disease and dislocation: the impact of refugee movements on the geography of malaria in NWFP, Pakistan. Soc Sci Med 52(7):1057-1069

Kazmi JH, Usery L (2001) Application of remote sensing and GIS for the monitoring of diseases: a unique research agenda for geographers. Remote Sens Rev 20(1):45-70

Kazmi JH, Mehdi R, Arsalan MH (2012) Karachi: the commercial capital of Pakistan. In: Misra RP (ed) Urbanisation in South Asia: focus on mega cities. Cambridge University Press India, New Delhi, India, pp 252-283

Khan HAA, Akram W, Shehzad K, Shaalan EA (2011) First report of field evolved resistance to agrochemicals in dengue mosquito, Aedes albopictus (Diptera: Culicidae), from Pakistan. Parasite Vector 4:146

Nalin DR, Mahood F, Rathor H, Muttalib A, Sakai R, Chowdhry MA, Safdar G, Munir M, Suleiman M, Bashir M, Mujtaba SML (1985) A point survey of peri-urban and urban malaria in Karachi. J Trop Med Hyg 88(1):7-15

Naqi SA (2010) Development of automated mapping/facility management system in Pakistan: a GIS evaluation for natural gas pipeline distribution and transmission network. Department of Geography, University of Karachi, PhD dissertation

Qamar SA (2005) Clinical investigation and diagnosis of malaria parasites and their vectors among population of Karachi on District level correlated with environmental and home management. PhD Dissertation, Department of Zoology, University of Karachi, p 113, http://eprints.hec.gov.pk/1405/1/1108. html.htm. Accessed 15 Sep 2012

Qureshi S (2010) The fast growing megacity Karachi as a frontier of environmental challenges: urbanization and contemporary urbanism issues. J Geogr Reg Plann 3(11):306-321

Qureshi S, Breuste JH, Lindley SJ (2010a) Green space functionality along an urban gradient in Karachi, Pakistan: a socio-ecological study. Hum Ecol 38(2):283-294 
Qureshi S, Kazmi SJH, Breuste JH (2010b) Ecological disturbances due to high cutback in the green infrastructure of Karachi: analyses of public perception about associated health problems. Urban Forest Urban Greening 9(3):187-198

Ross ES, Roberts HR (1943) Mosquito atlas. Part II. Eighteen old world anophelines important to malaria, The American Entomological Society, The Academy of Natural Sciences, Philadelphia

Rueda LM (2004) Pictorial keys for the identification of mosquitoes (Diptera: Culicidae) associated with dengue virus transmission. In: Zootaxa, vol 589. Magnolia Press, New Zealand, p 60

Shaikh S (2010) Predicting spatial distribution of mosquito-borne diseases in Karachi through SRS techniques. PhD dissertation, Department of Geography, University of Karachi, pp 126-132, http://eprints.hec.gov.pk/6607/. Accessed 15 Sep 2012

Tahir HM, Butt A, Khan SY (2009) Response of Culex quinquefasciatus to deltamethrin in Lahore District. J Parasitol Vector Biol 1(3):019-024

Walter Reed Biosystematics Unit (2001) Culicidae catalog. Smithsonian Institution, Washington DC, USA, http://wrbu.org

World Health Organization (2011) World malaria report. World Health Organization, Geneva, Switzerland

World Health Organization (2012) Global strategy for dengue prevention and control 2012-2020. World Health Organization, Geneva, Switzerland

Zaidi RH, Kazmi JH (1997) Studies on ecology, distribution and population dynamics of malarial pathogens in the province of Sindh: Pakistan. Proc Parasitol 21:77-84

Zaidi IH, Kazmi JH (2010) Resurgence of malaria in Pakistan: a geographical evaluation. In: Akhtar R, Dutt A, Wadhwa V (eds) Malaria in Asia: eradication, resurgence and diffusion during the second half of the twentieth century. Springer-Verlag, New York, pp 123-139

doi:10.1186/s13717-014-0012-y

Cite this article as: Shaikh et al: Monitoring the diversity of malaria and dengue vector in Karachi: studying variation of genera and subgenera of mosquitoes under different ecological conditions. Ecological Processes 2014 3:12.

\section{Submit your manuscript to a SpringerOpen ${ }^{\circ}$ journal and benefit from:}

- Convenient online submission

- Rigorous peer review

- Immediate publication on acceptance

- Open access: articles freely available online

- High visibility within the field

- Retaining the copyright to your article

Submit your next manuscript at $\gg$ springeropen.com 